\title{
Optimasi Proses Cutting Material Akrilik pada CNC Laser G-Weike LC6090 dengan Metode Simplex Centroid Design dan Optimasi Plot Multirespon
}

\author{
Tian Marcelina ${ }^{1}$, Dewa Kusuma Wijaya ${ }^{1 *}$, Rudi Tjahyono ${ }^{1}$, Herwin Suprijono ${ }^{1}$ \\ ${ }^{1}$ Program Studi Teknik Industri, Universitas Dian Nuswantoro Semarang, 50131 \\ *Korespondensi penulis: dewa.kuja@dsn.dinus.ac.id \\ (Received: 09-04-2021; Revised: 20-04-2021; Accepted: 27-04-2021)
}

\begin{abstract}
Operation of the G-Weike LC6090 CNC laser machine for cutting process uses the appropriate parameter settings in order to cut material optimally. It is known that $\mathrm{CNC}$ laser parameter settings on the machine are carried out by estimation or assumption because there is no reference or tabulation of parameter level settings on the machine which causes cutting process on the CNC laser to be less than optimal. Machine setting errors can result in mismatches of process results, so that the setting process is repeated on a trial error basis. This research is a continuation of previous research related to the optimization of the engraving process. This research focuses on optimizing the parameter setting level of the G-Weike LC6090 CNC laser machine for cutting process. The material used is acrylic with $3 \mathrm{~mm}, 5 \mathrm{~mm}$, and 10mm thickness. The setting parameters used are cutting speed and laser power. The optimization method uses a combination of Simplex Centroid Design and multi-response plot optimization. The response parameters used are actual processing time, dimensions of the length and width of the cut. The results of this study indicate that the optimal level of cutting process settings for $3 \mathrm{~mm}$ thickness acrylic is $1.93037 \mathrm{~mm} / \mathrm{s}$ for speed and $56.6963 \%$ for power. Acrylic with a thickness of $5 \mathrm{~mm}$ obtained an optimal level setting of $2.6 \mathrm{~mm} / \mathrm{s}$ for speed and $55 \%$ for power. $10 \mathrm{~mm}$ thick acrylic obtained the optimal setting level of $1.1535 \mathrm{~mm} / \mathrm{s}$ for speed and $59.539 \%$ for power. $59.539 \%$ for power.
\end{abstract}

Keywords: CNC laser, cutting, optimization, Simplex Centroid Design, multi-response plot.

\begin{abstract}
Abstrak. Operasional mesin CNC laser G-Weike LC6090 untuk proses cutting menggunakan seting parameter yang sesuai agar dapat memotong material secara optimal. CNC laser tersebut diketahui seting parameter pada mesin dilakukan secara perkiraan atau asumsi dikarenakan tidak adanya acuan tabulasi level parameter seting pada mesin tersebut yang menyebabkan proses cutting pada CNC laser tersebut kurang optimal. Kesalahan seting mesin dapat mengakibatkan ketidaksesuaian hasil proses, sehingga proses seting diulang kembali secara trial error. Penelitian ini merupakan lanjutan penelitian sebelumnya terkait optimasi proses engraving. Penelitian ini berfokus terhadap optimasi level seting parameter mesin CNC laser GWeike LC6090 untuk proses cutting. Material yang digunakan adalah akrilik berketebalan $3 \mathrm{~mm}, 5 \mathrm{~mm}$, dan $10 \mathrm{~mm}$. Parameter seting yang digunakan adalah kecepatan potong (speed) dan kekuatan laser (power). Metode optimasi menggunakan kombinasi Simplex Centroid Design dan optimasi plot multirespon. Parameter respon yang digunakan adalah waktu aktual proses, dimensi panjang dan lebar dari hasil potong. Hasil penelitian ini menunjukkan level seting proses cutting yang optimal untuk akrilik berketebalan $3 \mathrm{~mm}$ sebesar $1.93037 \mathrm{~mm} / \mathrm{s}$ untuk speed dan $56.6963 \%$ untuk power. Akrilik berketebalan 5mm diperoleh level seting optimal sebesar 2.6 $\mathrm{mm} / \mathrm{s}$ untuk speed dan $55 \%$ untuk power. Akrilik berketebalan $10 \mathrm{~mm}$ diperoleh level seting optimal sebesar $1.1535 \mathrm{~mm} / \mathrm{s}$ untuk speed dan $59.539 \%$ untuk power.
\end{abstract}

Kata kunci: CNC laser, cutting, optimasi, simplex centroid design, plot multirespon. 


\section{PENDAHULUAN}

Penggunaan mesin CNC (Computer Numerical Control) telah diimplementasikan secara luas pada era industri modern saat ini untuk menggantikan peran manusia dalam suatu proses permesinan. Permesinan CNC banyak memberikan manfaat secara luas, salah satunya adalah kualitas dari hasil pengerjaan yang sangat presisi dan akurat. Jenis mesin CNC sendiri semakin bervariatif, diantaranya adalah CNC turning, CNC milling, CNC router, $\mathrm{CNC}$ laser bahkan proses pengelasan juga sudah mulai menggunakan permesinan CNC yaitu CNC welding dan masih banyak jenis CNC lainnya. Selain beberapa jenis CNC tersebut, prinsip kerja $\mathrm{CNC}$ juga diimplementasikan pada mesin 3D printer dengan berbagai variasi jenisnya.

Operasionalitas mesin CNC biasanya dimulai dari tahapan perancangan menggunakan CAD (Computer Aided Design) dimana pada proses ini desain dari objek akan dibuat terlebih dahulu menggunakan bantuan software gambar computer baik dalam format 2D ataupun 3D sesuai kebutuhan pengguna. Tahapan selanjutnya adalah dilakukan perancangan menggunakan CAM (Computer Aided Machining) dimana pada tahapan ini desain yang telah dibuat sebelumnya akan dirancang alur proses pengerjaannya (toolpath) dan dibuat syntax program permesinan menggunakan bahasa permesinan. Salah satu bahasa permesinan CNC yang kita kenal adalah gcode.

Mesin CNC yang akan dioperasionalkan tentunya harus sudah disiapkan data program input dari hasil perancangan CAD. Data program tersebut kemudian akan diinput ke mesin CNC melalui panel kontrol yang ada di mesin tersebut ataupun ke dalam komputer sebagai kontrol mesin apabila di beberapa tipe mesin CNC tidak menggunakan panel kontrol. Selanjutnya akan dilakukan input seting parameter mesin CNC yang tentunya berbeda di setiap jenis mesin CNC. Mesin CNC kemudian akan membaca gcode dari data tersebut untuk kemudian memproses sesuai dengan program yang sudah ditetapkan.
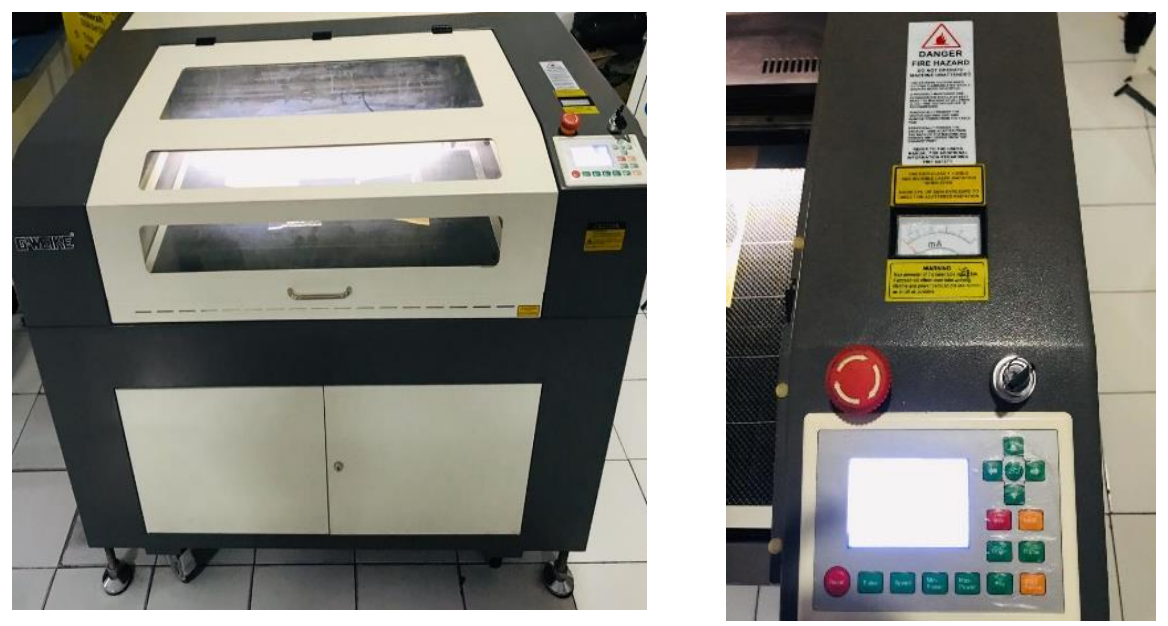

GAMBAR 1. CNC Laser G-Weike LC6090.

Penelitian ini menggunakan salah satu jenis mesin CNC yaitu CNC laser dengan merk GWeike tipe LC6090 sebagai objek. Operasionalitas mesin CNC laser g-Weike LC6090 sendiri seperti mesin CNC pada umumnya sesuai penjelasan di atas. Mesin CNC laser ini mampu melakukan 2 jenis proses permesinan yaitu potong (cutting) dan ukir (engraving). Proses cutting adalah proses yang digunakan untuk memotong material, sedangkan proses engraving adalah proses yang digunakan untuk menggores permukaan material sehingga hasil proses menjadi seperti ukiran. Material yang dapat diproses permesinan CNC laser G-weike LC6090 ini bervariatif diantaranya adalah akrilik, polikarbonat, PET, HDPE, LDPE, plyboard, MDF, LDF, HDF, dan lain sebagainya dengan ketebalan tertentu. Namun, mesin ini tidak dapat digunakan untuk memproses material logam oleh karena kemampuan daya laser yang tidak diperuntukkan untuk logam. Khusus material akrilik, 
sesuai informasi dari produsen mesin bahwa mesin CNC tersebut hanya mampu melakukan proses cutting dengan ketebalan maksimal $10 \mathrm{~mm}$ atau $1 \mathrm{~cm}$.

Kajian penelitian ini akan menggunakan objek permesinan CNC laser G-Weike LC6090 untuk proses cutting terhadap material berjenis akrilik dengan ketebalan yang bervariatif, yaitu $3 \mathrm{~mm}, 5 \mathrm{~mm}$, dan $10 \mathrm{~mm}$. Pemilihan ketebalan material akrilik tersebut disesuaikan dengan ketersediaan bahan akrilik yang ada di pasaran dan paling sering digunakan pada produk-produk berbasis akrilik.

Penelitian ini akan berfokus pada upaya optimasi proses cutting material akrilik dengan ketebalan bahan $3 \mathrm{~mm}, 5 \mathrm{~mm}$, dan $10 \mathrm{~mm}$. Optimasi proses cutting ini perlu dilakukan oleh karena mesin CNC tersebut pada operasionalnya tidak memiliki acuan tabulasi seting pada setiap parameter input mesinnya. Hal ini menyebabkan operator mesin tersebut sejauh ini ketika melakukan seting mesin hanya berdasarkan perkiraan atau asumsi saja. Hal ini tentu saja membuat proses permesinan cutting menjadi kurang optimal, dibuktikan dengan tabung $\mathrm{CO}_{2}$ penghasil laser yang lekas habis oleh karena seting penggunaan daya laser yang berlebih untuk memotong material atau bahkan material yang tidak terpotong oleh karena seting daya laser yang terlalu rendah, sehingga menyebabkan cacat (defect) material yang kemudian sebagian besar tidak dapat dimanfaatkan kembali dan dibuang.

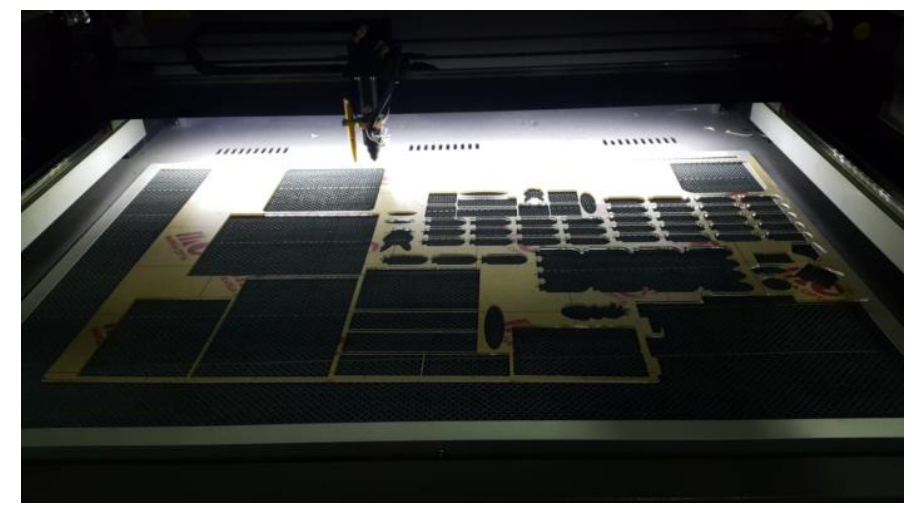

GAMBAR 2. Proses cutting material akrilik.

Parameter seting mesin CNC G-Weike LC6090 ini untuk proses cutting adalah untuk proses cutting pada kekuatan daya laser (power) dan kecepatan gerak potong (speed). Mesin CNC tersebut mampu melakukan proses cutting secara optimal untuk material akrilik apabila diketahui nilai seting power dan speed yang tepat, tentu saja material akrilik yang berbeda ketebalan nilai tingkat (level) setingnya juga berbeda-beda.

Penelitian ini menggunakan optimasi berbasis DoE (Design of Experiment) dengan metode SCD (Simplex Centroid Design) dan teknik optimasi plot multirespon. Seperti yang kita ketahui bahwa pemanfaatan DoE ini mampu mereduksi jumlah suatu pengujian ilmiah di dalam mencari solusi yang optimal. Adapun parameter respon yang digunakan pada penelitian ini adalah aktual waktu proses cutting, dimensi aktual panjang dan lebar hasil proses. Penelitian terkait optimasi untuk proses cutting material dengan menggunakan meisn CNC pernah dilakukan sebelumnya namun menggunakan CNC berjenis router terhadap material kayu mahoni, pada penelitian tersebut metode optimasi yang digunakan adalah full factorial design dan plot multirespon $[1,2]$. Optimasi permesinan CNC laser sendiri pernah dilakukan untuk proses cutting material berjenis PMMA (polymethyl methacrylate) dengan ketebalan $6 \mathrm{~mm}$ [3]. Penelitian lanjutan untuk proses cutting mesin $\mathrm{CNC}$ laser juga telah dilakukan terhadap material tipe komposit Al6061 - SiCp - $\mathrm{Al} 2 \mathrm{O}$ dengan menggunakan metode Response Surface dan Grey Relational Analysis untuk menentukan level seting optimal permesinan [4]. Penelitian ini menggunakan bahan akrilik, dimana akrilik merupakan salah satu material dengan tipe polimer. Optimasi proses cutting mesin CNC dengan bahan polimer sendiri juga pernah dilakukan [5], bahkan menggunakan bahan polimer berjenis polikarbonat [6]. 
Mengacu terhadap parameter seting penelitian ini yaitu power dan speed, penelitian sebelumnya juga pernah dilakukan untuk optimasi parameter tersebut pada mesin CNC laser namun ditujukan untuk proses engraving pada material kayu [7], dengan parameter yang sama penelitian dikembangkan menggunakan metode Response Surface untuk optimasi proses engraving material kayu [8]. Pengembangan parameter berupa kekasaran (roughness) dan laju pemotongan diterapkan pula pada proses cutting untuk material SUS316L menggunakan metode optimasi Taguchi Grey Relational Analysis [9]. Penelitian ini merupakan lanjutan dari penelitian sebelumnya dengan mesin CNC dan bahan material yang sama namun ditujukan untuk proses engraving, dimana pada penelitian tersebut metode optimasi yang digunakan adalah Simplex Centroid Design dan optimasi plot multirespon [10]. Diharapkan hasil kajian penelitian ini dapat menghasilkan nilai level seting yang optimal untuk proses cutting mesin CNC G-Weike LC6090 terhadap material akrilik dengan ketebalan $3 \mathrm{~mm}, 5 \mathrm{~mm}$, dan $10 \mathrm{~mm}$, sehingga dapat menjadi acuan tabulasi ketika mesin tersebut dioperasikan untuk memproses cutting material akrilik agar dapat lebih efektif dan efisien serta menghasilkan produk proses yang berkualitas dan masa pakai (lifetime) mesin dapat lebih lama.

\section{METODOLOGI}

Penelitian ini menggunakan metode Simplex Centroid Design dan teknik optimasi plot multirespon untuk melakukan optimasi level seting power dan speed dari mesin CNC laser Gweike-LC6090 terhadap material akrilik dengan ketebalan $3 \mathrm{~mm}, 5 \mathrm{~mm}$, dan $10 \mathrm{~mm}$. Adapun tahapan penelitian terangkum secara ringkas sebagai berikut:

1. Menentukan jenis material yaitu akrilik dan ketebalan material tersebut, dalam hal ini dipilih material akrilik dengan ketebalan $3 \mathrm{~mm}, 5 \mathrm{~mm}$, dan $10 \mathrm{~mm}$.

2. Membuat desain menggunakan bantuan software CAD sebagai desain sampel uji penelitian. Sampel uji penelitian ini berupa persegi dengan dimensi panjang $3 \mathrm{~cm}$ dan lebar $3 \mathrm{~cm}$.

3. Mengidentifikasi dan menentukan parameter seting mesin CNC, yaitu speed sebagai variabel $X_{1}$ dan power sebagai variabel $X_{2}$ beserta rentang level yang tersedia pada panel kontrol parameter seting mesin tersebut. Adapun rentang level dari parameter ditunjukkan pada tabel 1.

TABEL 1. Rentang nilai level parameter setting proses cutting mesin CNC G-Weike LC6090.

\begin{tabular}{lcccccccccc}
\hline \multirow{2}{*}{ Parameter } & \multicolumn{10}{c}{ Level setting } \\
\cline { 2 - 11 } & 1 & 2 & 3 & 4 & 5 & 6 & 7 & 8 & 9 & 10 \\
\hline Speed $(\mathbf{m m} / \mathbf{s})$ & 1 & 1.2 & 1.4 & 1.6 & 1.8 & 2 & 2.2 & 2.4 & 2.6 & 2.8 \\
Power $(\%)$ & 50 & 52 & 54 & 56 & 58 & 60 & 62 & 64 & 66 & 68 \\
\hline
\end{tabular}

4. Menentukan komposisi uji menggunakan metode Simplex Centroid Design, diketahui bahwa dengan 2 buah parameter seting mesin maka akan dihasilkan komposisi uji sebanyak 5 set untuk masing-masing ketebalan akrilik dengan masing-masing komposisi level setingnya.

5. Setelah jumlah komposisi uji ditetapkan dan desain sampel dibuat maka dilanjutkan dengan perancangan CAM menggunakan bantuan software bawaan mesin yaitu RDWorks. Pada proses CAM ini toolpath desain dibuat dan nilai parameter seting diinputkan sesuai set komposisi level yang telah ditetapkan untuk setiap ketebalan material akrilik yang digunakan. Selanjutnya program gcode dihasilkan untuk kemudian dilakukan operasi permesinan.

6. Program yang telah dibuat selanjutnya di-input kan ke mesin CNC laser G-Weike LC6090 melalui panel kontrol yang tersedia pada mesin tersebut dan proses cutting dilakukan.

7. Setiap selesai melakukan proses cutting per sampel uji-nya maka segera dilakukan pengukuran waktu aktual proses menggunakan alat ukur stopwatch berakurasi tinggi. Selanjutnya setelah keseluruhan proses cutting selesai dilakukan terhadap semua sampel uji maka dilanjutkan proses pengukuran hasil dimensi aktual panjang dan lebar 
dar hasil proses tersebut menggunakan alat ukur digital vernier caliper merk Insize berakurasi tinggi.

8. Hasil keseluruhan uji tersebut kemudian dicatat untuk setiap material akrilik dengan ketebalan $3 \mathrm{~mm}, 5 \mathrm{~mm}$, dan $10 \mathrm{~mm}$. Selanjutkan dilakukan analisa untuk mengetahui model matematis seting proses cutting dari hasil uji tersebut berdasarkan parameter seting untuk tiap ketebalan akrilik.

$$
Y=a X_{1}+b X_{2}+c X_{1} X_{2}
$$

$$
\begin{array}{ll}
\text { Dimana: } & Y=\text { Respon } \\
& X_{1}=\text { Variabel speed } \\
& X_{2}=\text { Variabel power } \\
& a=\text { Nilai koefisien } X_{1} \\
b & =\text { Nilai koefisien } X_{2} \\
c & =\text { Nilai koefisien korelasi variabel } X_{1} \text { dan } X_{2} .
\end{array}
$$

9. Setelah model matematis diperoleh, selanjutnya dilakukan teknik optimasi plot multirespon untuk diketahui hasil nilai level seting proses cutting yang optimal beserta plot grafik optimalnya menggunakan bantuan software optimasi.

10. Setelah hasil level seting optimal diperoleh, selanjutnya dilakukan validasi aktual dengan cara meng-input-kan nilai level seting tersebut ke mesin CNC laser G-Weike LC6090 untuk kemudian dilakukan pengukuran ulang untuk mengetahui besaran nilai error model yang dihasilkan dengan cara mengukur nilai deviasi.

\section{HASIL DAN PEMBAHASAN}

Hasil dan pembahasan penelitian ini akan menampilkan uji komposisi dari parameter seting mesin CNC G-Weike LC6090, model matematis, optimasi plot multirespon dan hasil validasi nilai level seting optimal dari proses cutting material akrilik untuk ketebalan bahan $3 \mathrm{~mm}, 5 \mathrm{~mm}$, dan $10 \mathrm{~mm}$. Sampel uji yang digunakan pada penelitian ini adalah bangun datar berupa persegi dengan dimensi panjang $3 \mathrm{~cm}$ dan lebar $3 \mathrm{~cm}$.

\section{Akrilik Ketebalan 3 mm}

Material akrilik dengan ketebalan $3 \mathrm{~mm}$ terlebih dahulu akan ditentukan komposisi uji berdasarkan kombinasi rentang seperti yang ditunjukkan pada tabel 1. Selanjutnya, dihasilkan 5 set nilai normalisasi komposisi uji seperti yang ditunjukkan pada tabel 2 .

TABEL 2. Normalisasi komposisi uji akrilik tebal $3 \mathrm{~mm}$.

\begin{tabular}{ccc}
\hline Komposisi & Speed $\left(\mathbf{X}_{\mathbf{1}}\right)$ & Power $\left(\mathbf{X}_{2}\right)$ \\
\hline 1 & 3 & 7 \\
2 & 9 & 1 \\
3 & 5 & 5 \\
4 & 7 & 3 \\
5 & 1 & 9 \\
\hline
\end{tabular}

\section{Uji Komposisi Seting}

Setelah diperoleh set komposisi uji dengan nilai normalisasinya, selanjutnya nilai tersebut akan dikonversi ke nilai parameter level seting aktual pada mesin CNC laser G-Weike LC6090 yang telah ditetapkan sebelumnya seperti yang ditunjukkan pada tabel 3.

TABEL 3. Aktual level setting komposisi uji akrilik tebal $3 \mathrm{~mm}$.

\begin{tabular}{ccc}
\hline Komposisi & $\boldsymbol{X}_{\mathbf{1}}(\mathbf{m m} / \mathbf{s})$ & $\boldsymbol{X}_{\mathbf{2}}(\boldsymbol{\%})$ \\
\hline 1 & 1.4 & 62 \\
2 & 2.5 & 50 \\
3 & 1.8 & 58 \\
4 & 2.2 & 54 \\
5 & 1 & 66 \\
\hline
\end{tabular}

Hasil konversi nilai parameter level seting aktual untuk set komposisi uji di atas selanjutnya akan diimplementasikan ke mesin CNC laser G-Weike LC6090 untuk dilakukan proses cutting sampel uji terhadap material akrilik ketebalan $3 \mathrm{~mm}$. Oleh karena terdapat 5 set 
sampel uji maka akan dihasilkan 5 sampel hasil pengujian proses cutting. Hasil uji tersebut akan diukur berdasarkan parameter multirespon yang telah ditetapkan yaitu waktu proses aktual dalam satuan menit, dimensi aktual panjang dan lebar hasil proses. Hasil pengukuran tersebut ditunjukkan pada tabel 4.

TABEL 4. Hasil uji komposisi proses cutting akrilik tebal $3 \mathrm{~mm}$.

\begin{tabular}{cccccc}
\hline Komposisi & $\boldsymbol{X}_{\mathbf{1}}(\mathbf{m m} / \mathbf{s})$ & $\boldsymbol{X}_{\mathbf{2}}(\boldsymbol{\%})$ & Waktu Proses (menit) & Panjang (cm) & Lebar $(\mathbf{c m})$ \\
\hline 1 & 1.4 & 62 & 1.004167 & 2.98 & 2.98 \\
2 & 2.5 & 50 & 0.8 & 0 & 0 \\
3 & 1.8 & 58 & 1.001167 & 3 & 2.95 \\
4 & 2.2 & 54 & 0.916667 & 2.98 & 2.97 \\
5 & 1 & 66 & 2 & 3 & 2.96 \\
\hline
\end{tabular}

Pada tabel 4 ditunjukkan bahwa pada komposisi uji ke-1 dengan nilai level setting parameter $X_{1}$ sebesar 1.4 dan $X_{2}$ sebesar 62 maka didapatkan hasil aktual waktu proses cutting sebesar 1.004167 menit, dimensi aktual panjang $2.98 \mathrm{~cm}$, dan lebar $2.98 \mathrm{~cm}$. Komposisi uji ke- 5 dengan nilai level setting parameter $X_{1}$ sebesar 1 dan $X_{2}$ sebesar 66 maka didapatkan hasil aktual waktu proses cutting sebesar 2 menit, dimensi aktual panjang $3 \mathrm{~cm}$, dan lebar $2.96 \mathrm{~cm}$.

\section{Model Matematis}

Setelah nilai respon diketahui dari hasil pengukuran terhadap 5 set komposisi uji di atas, maka selanjutnya dilakukan analisis hasil respon tersebut agar didapatkan formulasi model matematis proses cutting material akrilik ketebalan $3 \mathrm{~mm}$.

$$
\begin{aligned}
& \text { Waktu Proses }\left(Y_{1}\right)=0.103156 X_{1}+0.227531 X_{2}+(-0.029943) X_{1} X_{2} \\
& \text { Panjang }\left(Y_{2}\right)=-0.091729 X_{1}+0.208271 X_{2}+0.106429 X_{1} X_{2} \\
& \text { Lebar }\left(Y_{3}\right)=-0.091068 X_{1}+0.205432 X_{2}+0.105893 X_{1} X_{2}
\end{aligned}
$$

\section{Optimasi}

Setelah model matematis diketahui, selanjutnya dilakukan optimasi mennggunakan model matematis tersebut berdasarkan fungsi tujuan (objective function) dan batasan (constraint) yang dikehendaki. Optimasi yang digunakan adalah plot multirespon seperti yang ditunjukkan pada tabel 5.

TABEL 5. Optimasi plot multirespon akrilik ketebalan $3 \mathrm{~mm}$.

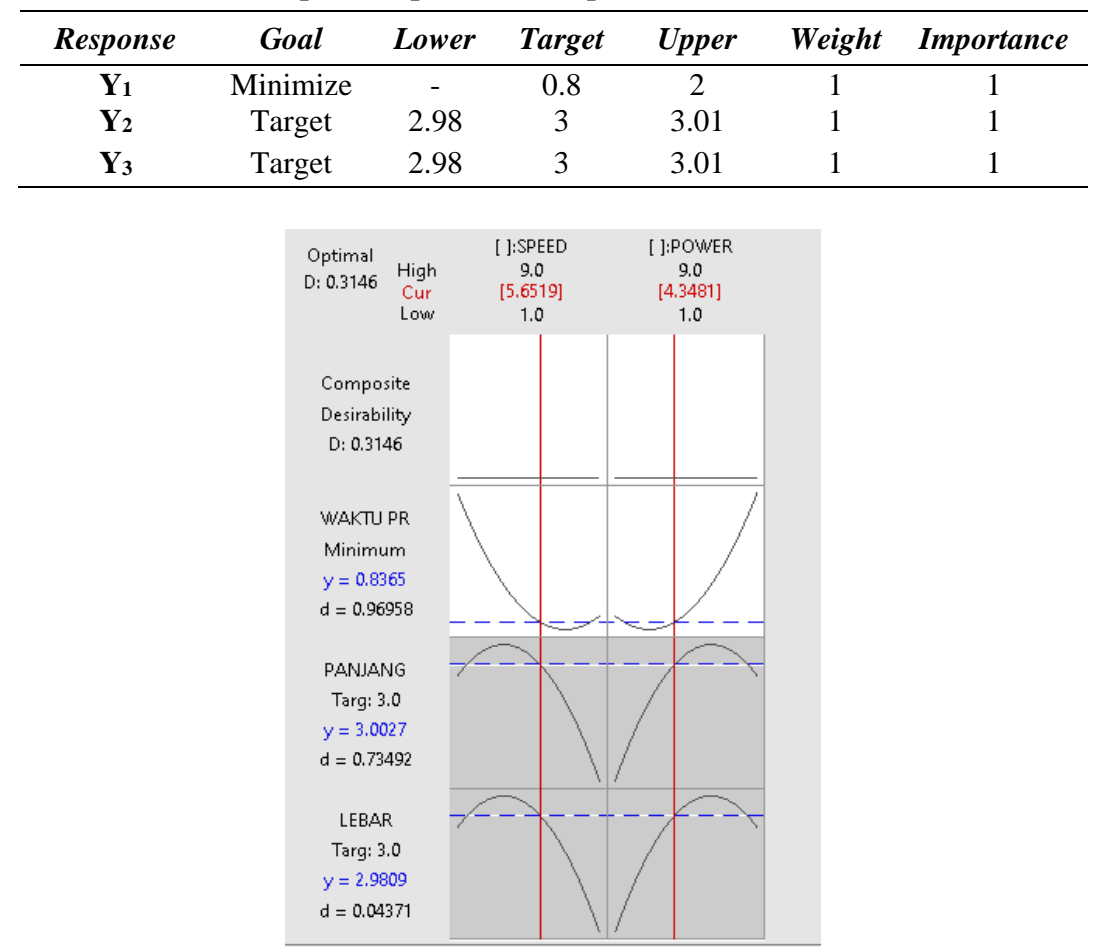

GAMBAR 3. Grafik plot multirespon level setting optimal akrilik ketebalan $3 \mathrm{~mm}$. 
Dimensi aktual panjang dan lebar dikehendaki nilai target sebesar 3 dengan batas atas maksimal sebesar 3.01 dan batas bawah minimal 2.98. Hasil nilai optimal level parameter seting terhadap parameter respon diketahui dengan plot grafik multirespon seperti yang ditunjukkan pada gambar 3 .

Grafik plot multirespon pada gambar 3 menunjukkan level setting optimal pada proses cutting material akrilik ketebalan $3 \mathrm{~mm}$, diketahui untuk nilai level optimal seting speed sebesar 1.93037 dan power sebesar 56.6963 akan diperoleh hasil aktual waktu proses sebesar 0.83655 menit, dimensi aktual panjang $3.00265 \mathrm{~cm}$ dan lebar $2.98087 \mathrm{~cm}$ dari hasil prosesnya.

\section{Akrilik Ketebalan 5 mm}

Material akrilik dengan ketebalan 5mm terlebih dahulu akan ditentukan komposisi uji berdasarkan kombinasi rentang seperti yang ditunjukkan pada table 1. Selanjutnya, akan dihasilkan sebanyak 5 set nilai normalisasi komposisi uji seperti yang ditunjukkan pada tabel 6.

TABEL 6. Normalisasi komposisi uji akrilik tebal $5 \mathrm{~mm}$.

\begin{tabular}{ccc}
\hline Komposisi & Speed $\left(\mathbf{X}_{\mathbf{1}}\right)$ & Power $\left(\mathbf{X}_{\mathbf{2}}\right)$ \\
\hline 1. & 7 & 3 \\
2. & 3 & 7 \\
3. & 5 & 5 \\
4. & 9 & 1 \\
5. & 1 & 9 \\
\hline
\end{tabular}

\section{Uji Komposisi Seting}

Setelah diperoleh set komposisi uji dengan nilai normalisasinya, selanjutnya nilai tersebut akan dikonversi ke nilai parameter level seting aktual pada mesin CNC laser G-Weike LC6090 yang telah ditetapkan sebelumnya seperti yang ditunjukkan pada tabel 7.

TABEL 7. Aktual level setting komposisi uji akrilik tebal $5 \mathrm{~mm}$.

\begin{tabular}{ccc}
\hline Komposisi & $\boldsymbol{X}_{\mathbf{1}}(\mathbf{m m} / \mathbf{s})$ & $\boldsymbol{X}_{\mathbf{2}}(\boldsymbol{\%})$ \\
\hline 1 & 2.2 & 59 \\
2 & 1.4 & 67 \\
3 & 1.8 & 63 \\
4 & 2.6 & 55 \\
5 & 1 & 68 \\
\hline
\end{tabular}

Hasil konversi nilai parameter level seting aktual untuk set komposisi uji di atas selanjutnya akan diimplementasikan ke mesin CNC laser G-Weike LC6090 untuk dilakukan proses cutting sampel uji terhadap material akrilik ketebalan $5 \mathrm{~mm}$. Oleh karena terdapat 5 set sampel uji maka akan dihasilkan 5 sampel hasil pengujian proses cutting. Hasil uji tersebut akan diukur berdasarkan parameter multirespon yang telah ditetapkan yaitu waktu proses aktual dalam satuan menit, dimensi aktual panjang dan lebar hasil proses. Hasil pengukuran tersebut ditunjukkan pada tabel 8 .

TABEL 8. Hasil uji komposisi proses cutting akrilik tebal $5 \mathrm{~mm}$.

\begin{tabular}{cccccc}
\hline Komposisi & $\boldsymbol{X}_{\mathbf{1}}(\mathbf{m m} / \mathbf{s})$ & $\boldsymbol{X}_{\mathbf{2}}(\boldsymbol{\%})$ & Waktu proses (menit) & Panjang $(\mathbf{c m})$ & Lebar $(\mathbf{c m})$ \\
\hline 1 & 2.2 & 59 & 0.916667 & 3 & 2.99 \\
2 & 1.4 & 67 & 1.004333 & 3 & 2.94 \\
3 & 1.8 & 63 & 1.0015 & 2.99 & 2.94 \\
4 & 2.6 & 55 & 0.8 & 3 & 2.99 \\
5 & 1 & 68 & 2.000167 & 3 & 2.91 \\
\hline
\end{tabular}

Pada tabel 8 ditunjukkan bahwa pada komposisi uji ke-1 dengan nilai level setting parameter $X_{1}$ sebesar 2.2 dan $X_{2}$ sebesar 59 maka didapatkan hasil aktual waktu proses cutting sebesar 0.916667 menit, dimensi aktual panjang $3 \mathrm{~cm}$, dan lebar $2.99 \mathrm{~cm}$. Komposisi uji ke-5 dengan nilai level setting parameter $X_{1}$ sebesar 1 dan $X_{2}$ sebesar 68 maka didapatkan hasil aktual waktu proses cutting sebesar 2.000167 menit, dimensi aktual panjang $3 \mathrm{~cm}$, dan lebar $2.91 \mathrm{~cm}$. 


\section{Model Matematis}

Setelah nilai respon diketahui dari hasil pengukuran terhadap 5 set komposisi uji di atas, maka selanjutnya dilakukan analisis hasil respon tersebut agar didapatkan formulasi model matematis proses cutting material akrilik ketebalan $5 \mathrm{~mm}$.

$$
\begin{aligned}
& \text { Waktu Proses }\left(Y_{1}\right)=0.103142 X_{1}+0.227542 X_{2}+(-0.029935) X_{1} X_{2} \\
& \text { Panjang }\left(Y_{2}\right)=0.300407 X_{1}+0.300407 X_{2}+(-0.000357) X_{1} X_{2} \\
& \text { Lebar }\left(Y_{3}\right)=0.300346 X_{1}+0.289846 X_{2}+0.000179 X_{1} X_{2}
\end{aligned}
$$

\section{Optimasi}

Setelah model matematis diketahui, selanjutnya dilakukan optimasi mennggunakan model matematis tersebut berdasarkan objective function dan constraint yang dikehendaki. Optimasi yang digunakan adalah plot multirespon seperti yang ditunjukkan pada tabel 9.

TABEL 9. Optimasi plot multirespon akrilik ketebalan $5 \mathrm{~mm}$.

\begin{tabular}{ccccccc}
\hline Response & Goal & Lower & Target & Upper & Weight & Importance \\
\hline $\mathbf{Y}_{\mathbf{1}}$ & Minimize & - & 0.8 & 2.00016666 & 1 & 1 \\
$\mathbf{Y}_{\mathbf{2}}$ & Target & 2.98 & 3 & 3.01 & 1 & 1 \\
$\mathbf{Y}_{\mathbf{3}}$ & Target & 2.98 & 3 & 3.01 & 1 & 1 \\
\hline
\end{tabular}

Pada optimasi plot multirespon seperti yang diketahui dari tabel 9, parameter respon menggunakan waktu proses aktual, dimensi actual panjang dan lebar hasil proses. Waktu proses aktual memiliki fungsi tujuan minimasi dengan nilai batas atas adalah 2.00012 dan dikehendaki nilai target 0.8. Dimensi aktual panjang dan lebar dikehendaki nilai target sebesar 3 dengan batas atas maksimal sebesar 3.01 dan batas bawah minimal 2.98. Hasil nilai optimal level parameter setting terhadap parameter respon diketahui dengan plot grafik multirespon seperti yang ditunjukkan pada gambar 4 .

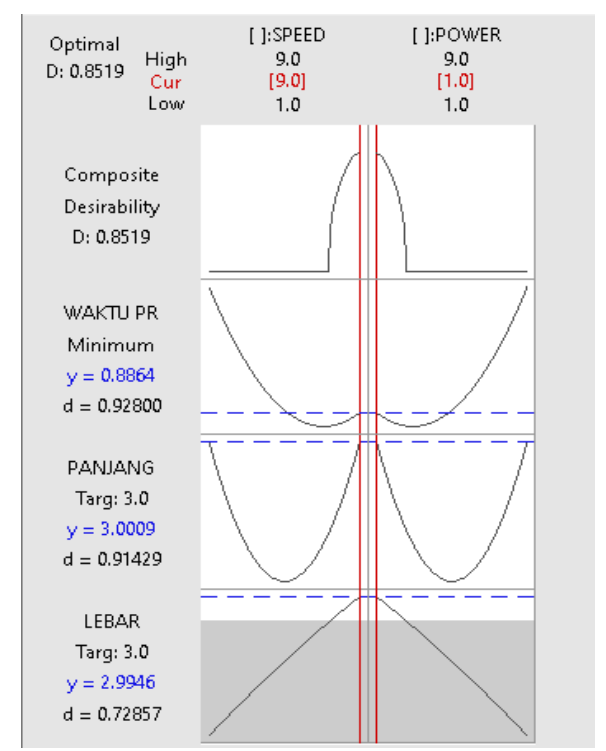

GAMBAR 4. Grafik plot multirespon level setting optimal akrilik ketebalan $5 \mathrm{~mm}$.

Grafik plot multirespon pada gambar 4 menunjukkan level setting optimal pada proses cutting material akrilik ketebalan $3 \mathrm{~mm}$, diketahui untuk nilai level optimal seting speed sebesar $2.6 \mathrm{~mm} / \mathrm{s}$ dan power sebesar 55\% akan diperoleh hasil aktual waktu proses sebesar 0.88641 menit, dimensi aktual panjang $3.00086 \mathrm{~cm}$ dan lebar $2.99457 \mathrm{~cm}$ dari hasil prosesnya.

\section{Akrilik Ketebalan 10 mm}

Material akrilik dengan ketebalan $10 \mathrm{~mm}$ terlebih dahulu akan ditentukan komposisi uji berdasarkan kombinasi rentang seperti yang ditunjukkan pada tabel 1 di atas. Selanjutnya, 
akan dihasilkan sebanyak 5 set nilai normalisasi komposisi uji seperti yang ditunjukkan pada tabel 10.

TABEL 10. Normalisasi komposisi uji akrilik tebal $10 \mathrm{~mm}$.

\begin{tabular}{ccc}
\hline Komposisi & Speed $\left(\mathbf{X}_{\mathbf{1}}\right)$ & Power $\left(\boldsymbol{X}_{\mathbf{2}}\right)$ \\
\hline 1 & 9 & 1 \\
2 & 7 & 3 \\
3 & 3 & 7 \\
4 & 1 & 9 \\
5 & 5 & 5 \\
\hline
\end{tabular}

\section{Uji Komposisi Setting}

Setelah diperoleh set komposisi uji dengan nilai normalisasinya, selanjutnya nilai tersebut akan dikonversi ke nilai parameter level setting aktual pada mesin CNC laser G-Weike LC6090 yang telah ditetapkan sebelumnya seperti yang ditunjukkan pada tabel 11.

TABEL 11. Aktual level setting komposisi uji akrilik tebal $10 \mathrm{~mm}$.

\begin{tabular}{ccc}
\hline Komposisi & $\boldsymbol{X}_{\mathbf{1}}(\mathbf{m m} / \mathbf{s})$ & $\boldsymbol{X}_{\mathbf{2}}(\boldsymbol{\%})$ \\
\hline 1 & 1.8 & 57.6 \\
2 & 1.6 & 58.2 \\
3 & 1.2 & 59.4 \\
4 & 1 & 60 \\
5 & 1.4 & 58.8 \\
\hline
\end{tabular}

Hasil konversi nilai parameter level seting aktual untuk set komposisi uji di atas selanjutnya akan diimplementasikan ke mesin CNC laser G-Weike LC6090 untuk dilakukan proses cutting sampel uji terhadap material akrilik ketebalan $10 \mathrm{~mm}$. Oleh karena terdapat 5 set sampel uji maka akan dihasilkan 5 sampel hasil pengujian proses cutting. Hasil uji tersebut akan diukur berdasarkan parameter multirespon yang telah ditetapkan yaitu waktu proses aktual dalam satuan menit, dimensi aktual panjang dan lebar hasil proses. Hasil pengukuran tersebut ditunjukkan pada tabel 12.

TABEL 12. Hasil uji komposisi proses cutting akrilik tebal $10 \mathrm{~mm}$.

\begin{tabular}{cccccc}
\hline Komposisi & $\boldsymbol{X}_{\mathbf{1}}(\mathbf{m m} / \mathbf{s})$ & $\boldsymbol{X}_{\mathbf{2}}(\boldsymbol{\%})$ & Waktu Proses (menit) & Panjang $(\mathbf{c m})$ & Lebar $(\mathbf{c m})$ \\
\hline 1 & 1.8 & 57.6 & 1.001167 & 0 & 0 \\
2 & 1.6 & 58.2 & 1.0025 & 0 & 0 \\
3 & 1.2 & 59.4 & 1.666667 & 3 & 2.98 \\
4 & 1 & 60 & 1.983333 & 2.97 & 2.99 \\
5 & 1.4 & 58.8 & 1.004333 & 2.98 & 2.97 \\
\hline
\end{tabular}

Pada tabel 12 ditunjukkan bahwa pada komposisi uji ke-1 dengan nilai level setting parameter $X_{1}$ sebesar 1.8 dan $X_{2}$ sebesar 57.6 maka didapatkan hasil aktual waktu proses cutting sebesar 1.001167 menit, dimensi aktual panjang $0 \mathrm{~cm}$, dan lebar $0 \mathrm{~cm}$ yang artinya material akrilik ketebalan $10 \mathrm{~mm}$ tersebut tidak terpotong. Material akrilik dengan ketebalan $10 \mathrm{~mm}$ tersebut mulai dapat terpotong pada komposisi uji ke-3 dengan nilai level seting parameter $X_{1}$ sebesar 1.2 dan $X_{2}$ sebesar 59.4 maka didapatkan hasil aktual waktu proses cutting sebesar 1.666667 menit, dimensi aktual panjang $3 \mathrm{~cm}$, dan lebar $2.98 \mathrm{~cm}$. Komposisi uji ke-5 dengan nilai level setting parameter $\mathrm{X}_{1}$ sebesar 1.4 dan $X_{2}$ sebesar 58.8 maka didapatkan hasil aktual waktu proses cutting sebesar 2.98 menit, dimensi aktual panjang $2.98 \mathrm{~cm}$, dan lebar $2.97 \mathrm{~cm}$.

\section{Model Matematis}

Setelah nilai respon diketahui dari hasil pengukuran terhadap 5 set komposisi uji di atas, maka selanjutnya dilakukan analisis hasil respon tersebut agar didapatkan formulasi model matematis proses cutting material akrilik ketebalan $10 \mathrm{~mm}$.

$$
\begin{aligned}
& \text { Waktu Proses }\left(Y_{1}\right)=0.106644 X_{1}+0.238069 X_{2}+(-0.023057) X_{1} X_{2} \\
& \text { Panjang }\left(Y_{2}\right)=-0.136179 X_{1}+0.310821 X_{2}+0.053929 X_{1} X_{2} \\
& \text { Lebar }\left(Y_{3}\right)=-0.13445 X_{1}+0.31355 X_{2}+0.05250 X_{1} X_{2}
\end{aligned}
$$




\section{Optimasi}

Setelah model matematis diketahui, selanjutnya dilakukan optimasi mennggunakan model matematis tersebut berdasarkan objective function dan constraint yang dikehendaki. Optimasi yang digunakan adalah plot multirespon seperti yang ditunjukkan pada tabel 13 .

TABEL 13. Optimasi plot multirespon akrilik ketebalan $10 \mathrm{~mm}$.

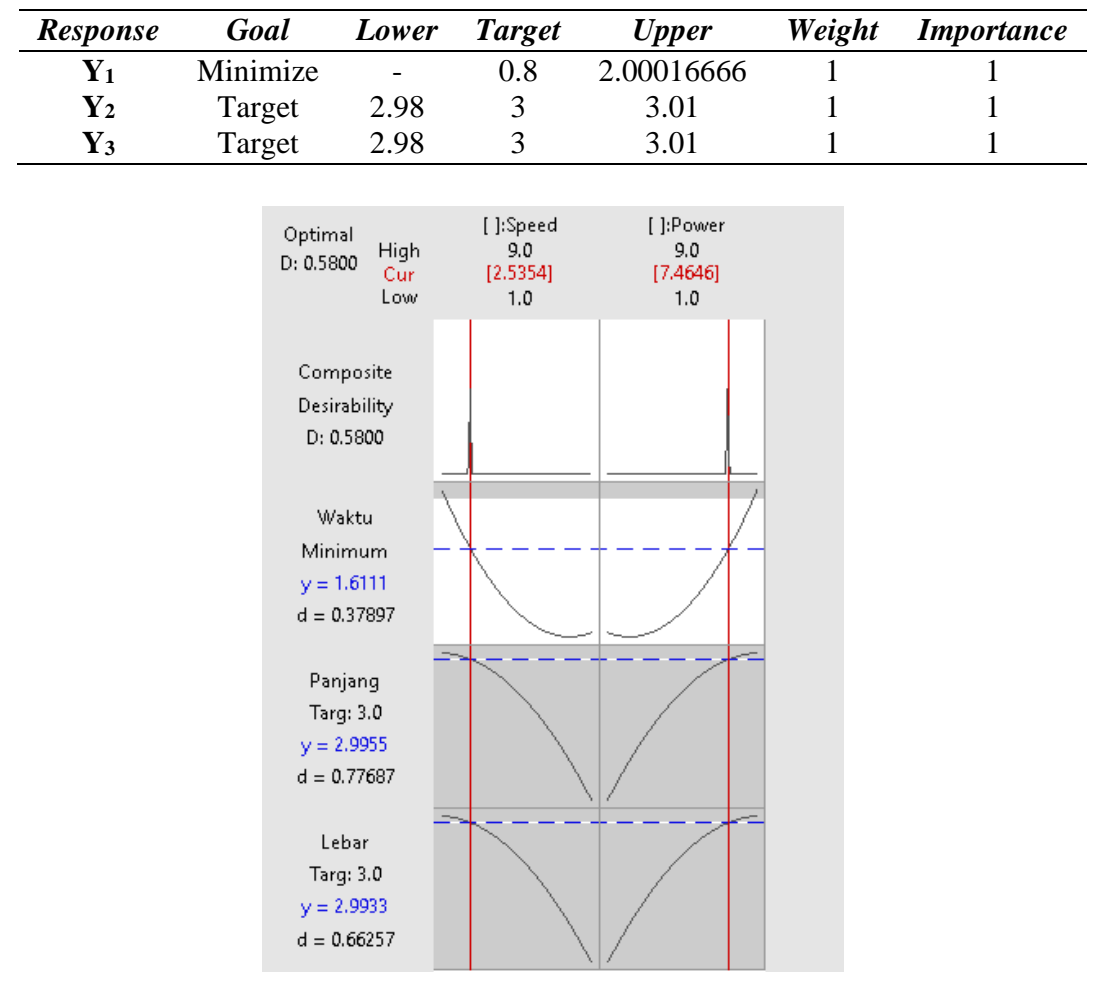

GAMBAR 5. Grafik plot multirespon level setting optimal akrilik ketebalan $10 \mathrm{~mm}$.

Pada optimasi plot multirespon seperti yang diketahui dari tabel 13, parameter respon menggunakan waktu proses aktual, dimensi actual panjang dan lebar hasil proses. Waktu proses aktual memiliki fungsi tujuan minimasi dengan nilai batas atas adalah 2.00012 dan dikehendaki nilai target 0.8 . Dimensi aktual panjang dan lebar dikehendaki nilai target sebesar 3 dengan batas atas maksimal sebesar 3.01 dan batas bawah minimal 2.98. Hasil nilai optimal level parameter seting terhadap parameter respon diketahui dengan plot grafik multirespon seperti yang ditunjukkan pada gambar 5. Grafik plot multirespon gambar 5 menunjukkan level setting optimal pada proses cutting material akrilik ketebalan $3 \mathrm{~mm}$, diketahui untuk nilai level optimal seting speed sebesar $1.1535 \mathrm{~mm} / \mathrm{s}$ dan power sebesar $59.539 \%$ akan diperoleh hasil aktual waktu proses sebesar 1.6111 menit, dimensi aktual panjang $2.99554 \mathrm{~cm}$ dan lebar $2.99325 \mathrm{~cm}$ dari hasil prosesnya.

\section{Validasi Model Matematis}

Validasi model digunakan untuk mengetahui seberapa akuratnya model matematis yang diperoleh dari hasil implementasi metode Simplex Centroid Design dan optimasi plot multirespon dalam menentukan nilai level parameter seting yang optimal dan hasil prediksi responnya terhadap hasil aktual setelah nilai level parameter seting diimplementasikan. Untuk mengetahui nilai akurasi model matematis maka akan diukur nilai standar error model seperti yang ditunjukkan pada tabel 14, 15, dan 16 .

TABEL 14. Level setting optimal proses cutting akrilik tebal $3 \mathrm{~mm}$.

\begin{tabular}{cccccc}
\hline Faktor & Level Seting & Respon & Prediksi & Hasil Uji & Standar Error \\
\hline \multirow{2}{*}{ Speed } & 1.93037 & Waktu Proses & 0.83655 & 1.0005 & 0.057865 \\
Power & 56.6963 & Panjang & 3.00265 & 3 & 0.000937 \\
& & Lebar & 2.98087 & 2.99 & 0.003228 \\
\hline
\end{tabular}


TABEL 15. Level setting optimal proses cutting akrilik tebal $5 \mathrm{~mm}$.

\begin{tabular}{cccccc}
\hline Faktor & Level Seting & Respon & Prediksi & Hasil Uji & Standar Error \\
\hline Speed & 2.6 & Waktu Proses & 0.88641 & 0.783333 & 0.036443 \\
Power & 55 & Panjang & 3.00086 & 3 & 0.000304 \\
& & Lebar & 2.99457 & 3 & 0.00192 \\
\hline
\end{tabular}

TABEL 16. Level setting optimal proses cutting akrilik tebal $10 \mathrm{~mm}$.

\begin{tabular}{cccccc}
\hline Faktor & Level Seting & Respon & Prediksi & Hasil Uji & Standar Error \\
\hline \multirow{2}{*}{ Speed } & 1.1535 & Waktu Proses & 1.6111 & 0.783333 & 0.275863 \\
Power & 59.539 & Panjang & 2.99554 & 3 & 0.001577 \\
& & Lebar & 2.99325 & 2.98 & 0.004685 \\
\hline
\end{tabular}

Pada tabel 14, 15, dan 16 di peroleh bahwa untuk material akrilik ketebalan $3 \mathrm{~mm}$ hasil validasi dengan prediksinya untuk semua parameter responnya terlihat tidak berbeda secara signifikan, hal ini ditunukkan dengan nilai standar error yang mendekati 0 yang artinya model matematis hasil optimasi tersebut adalah baik dan implementasi nilai level setting optimal pada mesin mampu memberikan output hasil yang cukup presisi. Material akrilik dengan ketebalan $5 \mathrm{~mm}$ dari hasil tabel di atas diketahui penggunaan metode optimasi mampu menghasilkan model matematis yang lebih baik, hal ini ditunjukkan dari nilai standar error yang lebih kecil dari setiap parameter responnya yang menunjukkan hasil prediksi model dengan aktualnya tidak berbeda secara signifikan. Selanjutnya untuk akrilik dengan ketebalan $10 \mathrm{~mm}$ telihat untuk parameter respon waktu proses terdapat deviasi antara hasil prediksi model matematis dengan implementasi aktual nilai level setingnya namun tidak terlalu signifikan karena masih berada pada nilai ambang batas, sementara untuk parameter respon lain antara prediksi model dengan aktualnya terlihat baik oleh karena tidak berbeda secara signifikan ditunjukkan dengan nilai standar error yang kecil.

\section{KESIMPULAN}

Hasil penelitian menggunakan metode Simplex Centroid Design dan optimasi plot multirespon untuk mengetahui nilai level setting optimal dari mesin CNC laser G-Weike LC6090 untuk proses cutting material akrilik, diketahui bahwa untuk akrilik ketebalan $3 \mathrm{~mm}$ nilai level seting optimal sebesar $1.93037 \mathrm{~mm} / \mathrm{s}$ untuk speed dan $56.6963 \%$ untuk power. Akrilik ketebalan $5 \mathrm{~mm}$ diketahui nilai level seting optimal adalah sebesar $2.6 \mathrm{~mm} / \mathrm{s}$ untuk speed dan 55\% untuk power. Akrilik ketebalan $10 \mathrm{~mm}$ diketahui nilai level seting optimal adalah sebesar $1.1535 \mathrm{~mm} / \mathrm{s}$ untuk speed dan $59.539 \%$ untuk power. Hasil validasi model matematis yang diperoleh dari metode penelitian ini mampu memberikan nilai standar error yang kecil, artinya hasil prediksi model matematis dengan implementasi aktual dari nilai level setting optimal tersebut mampu memberikan output hasil yang tidak berbeda secara signifikan untuk semua parameter responnya sehingga nilai level seting optimal tersebut dapat dijadikan acuan tabulasi seting mesin CNC laser G-Weike LC6090 untuk proses cutting material akrilik dengan ketebalan $3 \mathrm{~mm}, 5 \mathrm{~mm}$, dan $10 \mathrm{~mm}$. Penelitian selanjutnya dapat dilakukan dengan optimasi menggunakan metode yang lain untuk proses cutting dengan material dan ketebalan yang sama atau dapat dilanjutkan dengan penggunaan metode pada penelitian ini untuk proses cutting teradap jenis material yang berbeda.

\section{DAFTAR PUSTAKA}

[1] D. K. Wijaya, H. Suprijono, and D. S. Nugroho, "Optimasi Proses Cutting Mesin CNC Router G-Weike WK1212 dengan Metode Full Factorial Design dan Optimasi Plot Multi Respon," J. PASTI, vol. 14, no. 1, pp. 1-14, May 2020, doi: 10.22441/pasti.2020.v14i1.001. 
[2] H. Suprijono and D. K. Wijaya, "Optimasi Permesinan CNC Router untuk Proses Cutting Material Kayu Mahoni Menggunakan Mata Pahat End Mill 3mm Tungsten Carbide," J. Tek. Ind., vol. 10, no. 3, pp. 227-239, 2020, doi: 10.25105/jti.v10i3.8408.

[3] M. F. Chen, Y. Sen Ho, W. T. Hsiao, T. H. Wu, S. F. Tseng, and K. C. Huang, "Optimized laser cutting on light guide plates using grey relational analysis," Opt. Lasers Eng., vol. 49, no. 2, pp. 222-228, 2011, doi: 10.1016/j.optlaseng.2010.09.008.

[4] R. Adalarasan, M. Santhanakumar, and M. Rajmohan, "Optimization of laser cutting parameters for $\mathrm{Al} 6061 / \mathrm{SiCp} / \mathrm{Al} 2 \mathrm{O} 3$ composite using grey based response surface methodology (GRSM)," Meas. J. Int. Meas. Confed., vol. 73, pp. 596-606, 2015, doi: 10.1016/j.measurement.2015.06.003.

[5] I. A. Choudhury and S. Shirley, "Laser cutting of polymeric materials: An experimental investigation," Opt. Laser Technol., vol. 42, no. 3, pp. 503-508, 2010, doi: 10.1016/j.optlastec.2009.09.006.

[6] M. Moradi, O. Mehrabi, T. Azdast, and K. Y. Benyounis, "Enhancement of low power CO2 laser cutting process for injection molded polycarbonate," Opt. Laser Technol., vol. 96, pp. 208-218, 2017, doi: 10.1016/j.optlastec.2017.05.022.

[7] C. Leone, V. Lopresto, and I. De Iorio, "Wood engraving by Q-switched diodepumped frequency-doubled Nd:YAG green laser," Opt. Lasers Eng., vol. 47, no. 1 , pp. 161-168, 2009, doi: 10.1016/j.optlaseng.2008.06.019.

[8] A. Roy, N. Kumar, S. Das, and A. Bandyopadhyay, "Optimization of Pulsed Nd:YVO4 Laser Marking of AISI 304 Stainless Steel Using Response Surface Methodology," Mater. Today Proc., vol. 5, no. 2, pp. 5244-5253, 2018, doi: 10.1016/j.matpr.2017.12.107.

[9] R. R, K. BW, and A. I. Juniani, "OPTIMASI PARAMETER MESIN LASER CUTTING TERHADAP KEKASARAN DAN LAJU PEMOTONGAN PADA SUS 316L MENGGUNAKAN TAGUCHI GREY RELATIONAL ANALYSIS METHOD," J@ti Undip J. Tek. Ind., vol. 11, no. 2, p. 97, Jun. 2016, doi: 10.14710/jati.11.2.97-106.

[10] D. K. Wijaya and D. N. Izzhati, "Optimasi Setup Proses Engraving CNC Laser Cutting Material Akrilik Menggunakan Simplex Centroid Design dan Optimasi Respon," Din. Rekayasa, vol. 15, no. 1, pp. 1-10, Feb. 2019, doi: 10.20884/1.dr.2019.15.1.243. 